\title{
Aldehyde Oxidase Contributes to All-Trans-Retinoic Acid Biosynthesis in Human Liver ${ }^{[\mathrm{S}}$
}

\author{
Guo Zhong, Chris J. Seaman, 타ickson M. Paragas, Huaqing Xi, Karla-Luise Herpoldt, \\ Neil P. King, Jeffrey P. Jones, and Nina Isoherranen
}

Department of Pharmaceutics, School of Pharmacy, University of Washington, Seattle, Washington (G.Z., C.J.S., H.X., N.I.); Department of Chemistry, Washington State University, Pullman, Washington (E.M.P., J.P.J.); and Department of Biochemistry and Institute for Protein Design, University of Washington, Seattle, Washington (K.-L.H., N.P.K.)

Received October 25, 2020; accepted December 3, 2020

\section{ABSTRACT}

All-trans-retinoic acid (atRA) is a critical endogenous signaling molecule. atRA is predominantly synthesized from retinaldehyde by aldehyde dehydrogenase 1A1 (ALDH1A1), but aldehyde oxidase (AOX) may also contribute to atRA biosynthesis. The goal of this study was to test the hypothesis that $A O X$ contributes significantly to atRA formation in human liver. Human recombinant AOX formed atRA from retinaldehyde $\left(K_{m} \sim 1.5 \pm 0.4 \mu \mathrm{M} ; \mathrm{k}_{\text {cat }} \sim 3.6 \pm 2.0\right.$ minute $\left.^{-1}\right)$. In human liver $\mathbf{S 9}$ fractions (HLS9), atRA formation was observed in the absence of $\mathrm{NAD}^{+}$, suggesting $\mathrm{AOX}$ contribution to atRA formation. In the presence of $\mathrm{NAD}^{+}$, Eadie-Hofstee plots of atRA formation in HLS9 indicated that two enzymes contributed to atRA formation. The two enzymes were identified as AOX and ALDH1A1 based on inhibition of atRA formation by AOX inhibitor hydralazine (20\%-50\% inhibition) and ALDH1A1 inhibitor WIN18,446 (50\%-80\% inhibition). The expression of AOX in HLS9 was 9.4-24 pmol mg $\mathrm{mg}^{-1} \mathrm{S9}$ protein, whereas ALDH1A1 expression was 156-285 pmol $\mathrm{mg}^{-1} \mathrm{~s} 9$ protein measured by liquid chromatography-tandem mass spectrometry (LC-MS/MS) quantification of signature peptides. The formation velocity of atRA in the presence of $\mathrm{NAD}^{+}$correlated significantly with the expression of ALDH1A1 and AOX protein. Taken together, the data show that both AOX and ALDH1A1 contribute to atRA biosynthesis in the human liver, with ALDH1A1 being the high-affinity, low-capacity enzyme and AOX being the low-affinity, high-capacity enzyme. The results suggest that in the case of ALDH1A dysfunction or excess vitamin A, AOX may play an important role in regulating hepatic vitamin A homeostasis and that inhibition of AOX may alter atRA biosynthesis and signaling.

\section{SIGNIFICANCE STATEMENT}

This study provides direct evidence to show that human AOX converts retinaldehyde to atRA and contributes to hepatic atRA biosynthesis. The finding that AOX may be responsible for $\mathbf{2 0} \%-\mathbf{5 0} \%$ of overall hepatic atRA formation suggests that alterations in AOX activity via drug-drug interactions, genetic polymorphisms, or disease states may impact hepatic atRA concentrations and signaling and alter vitamin A homeostasis.

\section{Introduction}

Vitamin A (retinol) is an essential endogenous compound in all chordates. Retinol is first oxidized by retinol dehydrogenases to yield all-trans-retinaldehyde, which is further metabolized to all-transretinoic acid (atRA) (Napoli, 2012; Kedishvili, 2013). The active retinoid atRA binds to retinoic acid receptors and regulates various physiological processes, such as cell differentiation, T-cell activation, spermatogenesis, and lipid and glucose metabolism (Kedishvili, 2013). Liver, the major vitamin A storage organ, is an important site of retinoid metabolism. Aldehyde dehydrogenase 1A1 (ALDH1A1), one of the three members in the ALDH1A family in humans, is believed to be the major enzyme responsible for atRA biosynthesis in the liver, and the enzyme activity is $\mathrm{NAD}^{+}$-dependent (Arnold et al., 2015a, 2016).

This study was supported by National Institutes of Health National Institute of General Medical Sciences [Grant R01 GM111772].

https://doi.org/10.1124/dmd.120.000296.

S This article has supplemental material available at dmd.aspetjournals.org.
However, neither chemical inhibition of Aldh1a1 by WIN18,446 (Arnold et al., 2015a) nor global knockout of Aldh1a1 ${ }^{-/-}$(Fan et al., 2003) in mice completely abolishes liver atRA biosynthesis. WIN18,446 inhibited 44\% of atRA formation in mouse liver (Arnold et al., 2015a), and Aldh1a1 ${ }^{-/-}$mice are healthy and fertile at adulthood, with similar hepatic atRA concentrations as wild-type mice (Fan et al., 2003). Taken together, these findings suggest that other enzyme(s) contribute to hepatic atRA formation and maintenance of vitamin A homeostasis.

It has been proposed that aldehyde oxidase (AOX) contributes to at RA biosynthesis in select organs, including the liver. AOX is a cytosolic enzyme expressed in most animals and encoded by a single gene in humans. AOX generally metabolizes aldehydes and N-containing heterocyclic compounds (Pryde et al., 2010; Rashidi and Soltani, 2017), but unlike ALDH1As, catalysis by AOX does not require the cofactor $\mathrm{NAD}^{+}$. AOX enzymes in rabbit and mouse liver have been reported to catalyze retinaldehyde oxidation to yield atRA (Tomita et al., 1993; Huang et al., 1999). The data showing that retinaldehyde concentrations increased in the harderian gland of $\mathrm{Aox} 4^{-1-}$ mice and

ABBREVIATIONS: ACN, acetonitrile; afe, average fold error; ALDH1A, aldehyde dehydrogenase 1A; AOX, aldehyde oxidase; atRA, all-transretinoic acid; $\mathrm{CL}_{\text {int }}$, intrinsic clearance; CRBP, cellular retinol binding protein; $\mathrm{f}_{\mathrm{m}}$, fraction metabolized; HLS9, human liver $\mathrm{S} 9$ fraction; IS, internal standard; ISEF, intersystem extrapolation factor; KPi, potassium phosphate; LC-MS/MS, liquid chromatography-tandem mass spectrometry; $m / z$, mass-to-charge ratio; SIL-peptide, stable isotope-labeled peptide. 
atRA concentrations decreased in the harderian gland and skin of Aox $4^{-1-}$ mice in comparison with wild-type mice (Terao et al., 2009) suggest that AOX may play an important role in regulating atRA biosynthesis. The AOX family of enzymes has also been reported to be involved in testicular atRA biosynthesis in mice (Beedle et al., 2019), and hydralazine, an AOX inhibitor, decreased atRA formation in mouse liver S10 fractions by 45\% (Arnold et al., 2015a). Furthermore, both $\mathrm{NAD}^{+}$-dependent and -independent retinaldehyde metabolism was observed in soluble extracts of human liver and kidney (Ambroziak et al., 1999), strongly suggesting that AOX is involved in atRA biosynthesis. However, AOX is not typically included when atRA formation is considered. This is largely due to the lack of Aox knockout mouse models. The only available Aox $4^{-1-}$ mouse model did not show any major morphologic abnormalities or lethal phenotype that would be expected if atRA biosynthesis was significantly impaired (Terao et al., $2009,2020)$. In addition, at present no quantitative characterization of AOX contribution to atRA biosynthesis in specific tissues has been published. In this study, we hypothesized that aside from ALDH1A1, AOX makes a significant contribution to atRA formation in human liver. We aimed to quantitatively characterize atRA formation mediated by AOX in human liver and delineate the relative contribution of ALDH1A1 and AOX in hepatic atRA formation. This characterization is important for addressing altered atRA synthesis in human liver in various disease states and due to drug-drug interactions.

\section{Materials and Methods}

Chemicals, Reagents, Tissues, and Recombinant Enzymes. Retinaldehyde, $a t \mathrm{RA}, a t \mathrm{RA}_{-} \mathrm{d}_{5}, \mathrm{NAD}^{+}, \mathrm{NADPH}$, raloxifene, and hydralazine were purchased from Millipore Sigma (Burlington, MA). WIN18,446 was from Acros Organics (Geel, Belgium). All LC-MS/MS-grade solvents were purchased from Thermo Fisher Scientific (Waltham, MA). Pooled human liver S9 fractions (lot number 3212595, 27 donors with 12 male and 15 female) were purchased from Corning (Corning, NY). Human liver samples from three individual donors-HL136 (39 years old, Caucasian male), HL146 (10 years old Caucasian male), and HL149 (63 years old, Caucasian female)—were obtained from the tissue bank of University of Washington School of Pharmacy.

Expression and Purification of Recombinant Human ALDH1A1, AOX, and Cellular Retinol Binding Protein 1 and Preparation of Human Liver S9 Fractions. Recombinant human AOX was expressed, purified, and quantified as published previously (Barr et al., 2013; Paragas et al., 2017). Human recombinant ALDH1A1 was expressed in Escherichia coli as previously described (Arnold et al., 2015b) with several modifications. Briefly, frozen cell pellets were thawed on ice, resuspended with $25 \mathrm{ml}$ lysis buffer $(1 \mathrm{mg} / \mathrm{ml}$ of lysozyme, $500 \mathrm{mM} \mathrm{NaCl}$, $20 \mathrm{mM}$ Tris, $5 \mathrm{mM}$ imidazole, $\mathrm{pH}$ 7.4), and lysed at room temperature for 15 minutes with gentle shaking. The resuspended mixture was centrifuged at $18,000 \mathrm{~g}$ for 20 minutes. The supernatant was loaded into a HisTrap HP column (GE Healthcare Bio-Sciences, Marlborough, MA) using Biologic DuoFlow chromatography system (Bio-Rad Laboratories, Hercules, CA). The column was washed with $5 \times$ column volumes of wash buffer $(20 \mathrm{mM}$ Tris- $\mathrm{HCl}, 500 \mathrm{mM}$ $\mathrm{NaCl}, 20 \mathrm{mM}$ imidazole, $\mathrm{pH}$ 7.4), and ALDH1A1 was eluted with five column volumes of elution buffer ( $20 \mathrm{mM}$ Tris- $\mathrm{HCl}, 500 \mathrm{mM} \mathrm{NaCl}, 300 \mathrm{mM}$ imidazole, pH7.4). Fractions containing ALDH1A1 were concentrated and exchanged into HEDK buffer (10 mM Hepes-NaOH, $0.1 \mathrm{mM}$ EDTA, $0.5 \mathrm{mM}$ DTT, $100 \mathrm{mM}$ $\mathrm{KCl}, \mathrm{pH}$ 8.0) using a HiLoad 16/60 Superdex 200 column (GE Healthcare BioSciences) following the manufacturer's instructions. After the protein concentration was determined by a bicinchoninic acid protein assay (Thermo Fisher Scientific), purified ALDH1A1 was stored at $-20^{\circ} \mathrm{C}$ in HEDK buffer with $2 \mathrm{mM}$ tris(2-carboxyethyl)phosphine and 50\% glycerol.

The gene encoding CRBP1 was ordered from Integrated DNA Technologies (Coralville, IA) as a gBlock and cloned into pET28b (Novagen, Madison, WI) using Gibson assembly between the NdeI and XhoI endonuclease restriction sites. Cloning at this site incorporates an $\mathrm{N}$ terminal, thrombin cleavable, His-tag. The DNA and amino acid sequences are listed in Supplemental Table 1. The plasmid encoding CRBP1 was then transformed into the T7 Expression strain of E. coli (New England Biolabs, Ipswich, ME) for protein expression. Cells were grown in
Luria-Bertani (LB) medium supplemented with $50 \mathrm{mg} / \mathrm{l}$ of kanamycin at $37^{\circ} \mathrm{C}$ until an opptical density 600 of 0.6 was reached. Protein expression was induced by addition of isopropyl-thio- $\beta$-D-galactopyranoside to a final concentration of $1 \mathrm{mM}$. After induction, cells were allowed to grow for 16 hours at $18^{\circ} \mathrm{C}$ before harvesting by centrifugation. Cells pellets were lysed by sonication ( 2.5 minutes in 2-second pulses) in $50 \mathrm{mM}$ Tris ( $\mathrm{pH} 8$ ), $150 \mathrm{mM} \mathrm{NaCl}, 20 \mathrm{mM}$ imidazole, $0.05 \mathrm{mg} / \mathrm{ml}$ DNase, $0.05 \mathrm{mg} / \mathrm{ml} \mathrm{RNase}$, and $1 \mathrm{mM}$ phenylmethylsulfonyl fluoride. Lysate was centrifuged at $25,000 \mathrm{~g}$ for 25 minutes. Lysate supernatants were applied to HisTrap FF columns (GE Healthcare, Uppsala, Sweden) for purification by immobilized metal affinity chromatography on an AKTA pure fast protein liquid chromatography system (GE Healthcare). The protein of interest was eluted over a linear gradient of $20-500 \mathrm{mM}$ imidazole in a background of $50 \mathrm{mM}$ Tris ( $\mathrm{pH} 8)$ and $150 \mathrm{mM} \mathrm{NaCl}$ after washing with $\sim 10$ column volumes wash buffer (elution buffer with $20 \mathrm{mM}$ imidazole). Peak fractions were concentrated in $3 \mathrm{kDa}$ molecular weight cutoff centrifugal filters, sterile filtered $(0.22 \mu \mathrm{m})$, and dialyzed overnight to remove imidazole into a buffer containing $25 \mathrm{mM}$ Tris $(\mathrm{pH} 8)$ and $150 \mathrm{mM} \mathrm{NaCl}$. After dialysis, thrombin was added at a dilution of 1:2000 (v/v) and incubated overnight at $4^{\circ} \mathrm{C}$. To remove cleaved Histag fragments and any un-cleaved protein, the solution was applied to an equilibrated HisTrap FF column, and the flow-through was collected. The collected protein was again concentrated using a $3 \mathrm{kDa}$ molecular weight cutoff centrifugal filter and applied to a Superdex 200 Increase 10/300 GL size exclusion chromatography column (GE Healthcare) using $25 \mathrm{mM}$ Tris (pH 8) and $150 \mathrm{mM}$ $\mathrm{NaCl}$. Purified CRBP1 was stored at $-20^{\circ} \mathrm{C}$ with $20 \%$ glycerol.

To prepare HLS9 fractions, liver samples (140-170 mg) from three donors were homogenized on ice with homogenizing buffer [50 $\mathrm{mM}$ potassium phosphate (KPi) containing $250 \mathrm{mM}$ sucrose and $50 \mathrm{mM} \mathrm{KCl}, \mathrm{pH} 7.4]$ in a 5:1 ratio of buffer to liver weight. After centrifugation at $9000 \mathrm{~g}$ at $4^{\circ} \mathrm{C}$ for 30 minutes, the supernatant (HLS9) was collected, aliquoted, and stored at $-80^{\circ} \mathrm{C}$ until use. The protein concentration in each human liver S9 sample was measured using a bicinchoninic acid protein assay (Thermo Fisher Scientific).

General Protocol of Enzyme Incubations and atRA Quantification Using LC-MS/MS. Incubations were performed according to the following protocol unless otherwise stated: HLS9 or purified recombinant enzymes were first preincubated at $37^{\circ} \mathrm{C}$ for 3 minutes in $100 \mathrm{mM} \mathrm{KPi}$ buffer (pH7.4) in a final volume of $100 \mu \mathrm{l}$. The reactions were initiated by adding retinaldehyde. The incubation times were as described for each experiment in the following sections. When possible, a 30-second incubation time was used to avoid substrate depletion and time-dependent loss of enzyme activity. In incubations that had low product formation rates as a result of chemical inhibition or low enzyme expression, longer incubation periods (up to 3 minutes) were employed to allow sufficient sensitivity and detection of atRA formation while maintaining incubation time within the linear range. All the incubation times were sufficiently short to avoid timedependent loss of or decrease in enzyme activity for ALDH1A1 or AOX. Protein and time linearity was confirmed for all systems employed. After the predefined incubation time, the reactions were terminated by adding an equal volume of icecold acetonitrile (ACN) with $20 \mathrm{nM}$ atRA- $\mathrm{d}_{5}$ [internal standard (IS)]. The samples were centrifuged at $15,000 \mathrm{~g}$ at $4{ }^{\circ} \mathrm{C}$ for 10 minutes, and the supernatants were used for LC-MS/MS analysis. This method is referred to as "ACN precipitation method" in the following sections. For incubations with low product formation, incubation volume was increased to $500 \mu \mathrm{l}$. After adding an equal volume of icecold ACN with $4 \mathrm{nM}$ atRA-d $\mathrm{d}_{5}$ to stop the reaction, samples were processed using a hexane extraction method (Arnold et al., 2015b). In this method, each sample was extracted with $8 \mathrm{ml}$ of hexanes and centrifuged at $1000 \mathrm{~g}$ for 5 minutes, and the organic layer was transferred into a glass tube and dried under $\mathrm{N}_{2}$ flow. The residue was resuspended with $100 \mu 1$ of $80 \%$ ACN for LC-MS/MS analysis. Incubation time and concentrations of protein, substrate, inhibitor, and cofactor used for incubations are specified for each experiment in the following sections. All incubations were performed under yellow light to prevent retinoid degradation and isomerization. All cofactor solutions were freshly prepared before incubations. As minor nonenzymatic formation of $a t \mathrm{RA}$ was observed in incubations with retinaldehyde, incubations with no enzyme were included in each experiment and used for background subtraction. Unless described otherwise, all incubations were performed as duplicates or triplicates and repeated three times on separate days.

The formation of $a t \mathrm{RA}$ in incubations was measured by LC-MS/MS with AB Sciex 5500 quadrupole linear ion trap mass spectrometer (AB Sciex LLC, Framingham, MA) using positive ion athmospheric pressure chemical ionization 
probe and an Agilent 1290 Infinity ultra high performace liquid chromatography (Agilent Technologies, Santa Clara, CA) with a Kinetex C18 column $(1.7 \mu \mathrm{m}$, $100 \AA ̊ 2.1 \times 100 \mathrm{~mm}$; Phenomenex, Torrance, CA) for chromatographic separation. The mobile phase consisted of $\mathrm{H}_{2} \mathrm{O}$ with $0.1 \%$ formic acid (solvent $\mathrm{A}$ ) and $\mathrm{ACN}$ with $0.1 \%$ formic acid (solvent $\mathrm{B}$ ). The flow rate was $0.45 \mathrm{ml} / \mathrm{min}$, and the column temperature was set at $40^{\circ} \mathrm{C}$. The gradient started at $50 \% \mathrm{~B}$, increased to $95 \%$ B within 4.0 minutes, and then was kept at $95 \%$ B for 1 minute before returning to initial conditions. The injection volume was $20 \mu \mathrm{l}$ per sample. atRA was monitored with multiple-reaction monitoring transitions of mass-to-charge ratio $(\mathrm{m} / \mathrm{z}) 301>205$ and $301>123$, and $a t \mathrm{RA}^{-\mathrm{d}_{5}}$ was monitored with $\mathrm{m} / \mathrm{z}$ $306>208$. All MS/MS parameters were set as previously described (Arnold et al., 2015b). Peaks of $a t$ RA and IS were integrated using Analyst 1.6.3. All atRA quantification methods followed best practices as previously reported for quantification of atRA (Czuba et al., 2020). The peak area ratio of $a t \mathrm{RA}$ to IS was used to quantify atRA formation. For quantification, standard curves of atRA (five concentrations ranging from 2 to $37.5 \mathrm{nM}$ ) were constructed by spiking $a t \mathrm{RA}$ into KPi buffer, and standard curve samples were processed in parallel with incubation samples. The ratio of atRA to atRA- $\mathrm{d}_{5}$ (IS) peak area was plotted against $a t$ RA concentration ( $r^{2}$ values $>0.98$ for all curves) and was used to calculate the concentration of atRA formed in incubations (Arnold et al., 2015b). At least one representative experiment in replicates was analyzed by two different people in the laboratory to validate the analyses.

atRA Formation by Recombinant Human AOX, ALDH1A1, and HLS9. To measure enzyme kinetic parameters of atRA formation from retinaldehyde by AOX, $10 \mathrm{nM}$ recombinant AOX was incubated for 30 seconds with 11 concentrations of retinaldehyde ranging from $100 \mathrm{nM}$ to $7.5 \mu \mathrm{M}$. Samples were processed with the ACN precipitation method. Enzyme kinetic parameters, including $\mathrm{k}_{\mathrm{cat}}$ and Michaelis-Menten constant $\left(\mathrm{K}_{\mathrm{m}}\right)$, were obtained using GraphPad Prism 5.0 (GraphPad Software, La Jolla, CA) by fitting the Michaelis-Menten equation to the data. Enzyme kinetic parameters of atRA formation from retinaldehyde with recombinant human ALDH1A1 were measured as described previously (Arnold et al., 2015b). To test cofactor dependence of atRA formation with HLS9, pooled HLS9 $\left(0.02 \mu \mathrm{g}\right.$ protein $\left.\mu \mathrm{l}^{-1}\right)$ were incubated with $2 \mu \mathrm{M}$ retinaldehyde in the absence or presence of various cofactors. Tested cofactors and their final concentrations in incubations were $2 \mathrm{mM} \mathrm{NAD}^{+}, 2 \mathrm{mM} \mathrm{NADP}^{+}$, and $1 \mathrm{mM}$ NADPH. Incubation time was 30 seconds. Samples were processed with the ACN precipitation method. To perform kinetic characterization of atRA formation with HLS9, pooled HLS9 $\left(0.005 \mathrm{mg}\right.$ protein $\left.\mathrm{ml}^{-1}\right)$ were incubated in the presence or absence of $2 \mathrm{mM} \mathrm{NAD}^{+}$for 40 seconds with various concentrations of retinaldehyde ranging from $10 \mathrm{nM}$ to $10 \mu \mathrm{M}$. Samples were processed with the hexane extraction method. Enzyme kinetic parameters, including the maximum $a t \mathrm{RA}$ formation velocity $\left(\mathrm{V}_{\max }\right)$ and Michaelis-Menten constant in biologic matrix $\left(\mathrm{K}_{\mathrm{m}}\right)$, were obtained using GraphPad Prism 5.0 by fitting the Michaelis-Menten equation to the data. As two enzymes were involved in $a t$ RA formation in HLS9 when $\mathrm{NAD}^{+}$was present, a two-enzyme MichaelisMenten equation (eq. 1) was fit to the data to obtain kinetic parameters:

$$
v=\frac{V_{\max 1} \times[S]}{K_{m 1}+[S]}+\frac{V_{\max 2} \times[S]}{K_{m 2}+[S]}
$$

In eq. $1, \mathrm{~K}_{\mathrm{m}}$ of enzyme $1\left(K_{m 1}\right)$ was constrained to be the value obtained from incubations performed without $\mathrm{NAD}^{+}$, and $V_{\max 1}$ constrained to be larger than 400 pmol minute ${ }^{-1} \mathrm{mg}^{-1} \mathrm{~S} 9$ protein. To build Eadie-Hofstee plots, atRA formation velocity $(v)$ was plotted against $v /[S]$, in which $S$ is the substrate concentration.

Effects of CRBP1 on atRA Formation by AOX and ALDH1A1. The effect of CRBP1 on atRA formation by AOX and ALDH1A1 was tested with recombinant proteins and pooled HLS9. CRBP1-bound retinaldehyde (holo-CRBP1) was prepared by incubating $4 \mu \mathrm{M}$ retinaldehyde for 5 minutes at room temperature with $4 \mu \mathrm{M}$ CRBP1 in $100 \mathrm{mM} \mathrm{KPi}$ buffer (pH 7.4). The incubations were conducted with recombinant enzymes (5 nM AOX; $20 \mathrm{nM}$ ALDH1A1) or pooled HLS9 (0.005 mg protein $\mathrm{ml}^{-1}$ ) in $100 \mathrm{mM} \mathrm{KPi}$ buffer containing $2 \mathrm{mM} \mathrm{NAD}^{+}$. The total incubation volume was $300 \mu \mathrm{l}$ for recombinant enzymes and $1000 \mu \mathrm{l}$ for pooled HLS9. Incubations were initiated by adding holo-CRBP1 (200 nM final concentration) or retinaldehyde ( $200 \mathrm{nM}$ final concentration). The reaction was stopped by adding an equal volume of ice-cold ACN with $4 \mathrm{nM}$ atRA-d $\mathrm{d}_{5}$. The incubation time was 1,3 , and 2 minutes for recombinant AOX, ALDH1A1, and HLS9, respectively. Samples were processed using the hexane extraction method and analyzed using LC-MS/MS.

Inhibition of atRA Formation by AOX and ALDH1A1 Inhibitors Hydralazine, Raloxifene, and WIN18,446. Both hydralazine and raloxifene are known AOX inhibitors (Pryde et al., 2010; Strelevitz et al., 2012), whereas WIN18,446 is a selective ALDH1A inhibitor (Arnold et al., 2015a). To build $\mathrm{IC}_{50}$ curves of hydralazine and raloxifene against AOX and to test whether WIN18,446 inhibits AOX activity, $10 \mathrm{nM}$ recombinant human AOX was incubated with 0.5 $\mu \mathrm{M}$ retinaldehyde and five to eight concentrations of raloxifene $(1 \mathrm{nM}-5 \mu \mathrm{M})$, hydralazine $(1 \mathrm{nM}-100 \mu \mathrm{M})$, and WIN18,446 $(1-500 \mu \mathrm{M})$ for 2 minutes. All samples were processed with the $\mathrm{ACN}$ precipitation method. The $\mathrm{IC}_{50}$ values were determined by nonlinear regression using GraphPad Prism 5.0 as described previously (Thatcher et al., 2011).

To test whether hydralazine and raloxifene inhibit ALDH1A1 activity, $20 \mathrm{nM}$ ALDH1A1 was incubated with $0.2 \mu \mathrm{M}$ retinaldehyde, $2 \mathrm{mM} \mathrm{NAD}^{+}$, and hydralazine $(10 \mathrm{nM}-1 \mathrm{mM})$ or raloxifene $(1 \mathrm{nM}-5 \mu \mathrm{M})$ in buffer containing $150 \mathrm{mM} \mathrm{KCl}$ and $50 \mathrm{mM}$ Hepes- $\mathrm{NaOH}\left(\mathrm{pH}\right.$ 8.0). Incubations were initiated with the addition of $\mathrm{NAD}^{+}$. The incubation time was 5 minutes. Control groups were incubations with no inhibitor. All samples were processed with the ACN precipitation method. The percentage of control activity was calculated and plotted against inhibitor concentrations.

To determine the relative contribution to atRA formation by AOX and ALDH1A1 in human liver S9 fractions, pooled HLS9 and HLS9 from 3 individual liver donors $\left(0.01 \mathrm{mg}\right.$ protein $\left.\mathrm{ml}^{-1}\right)$ were incubated with inhibitors and $0.2 \mu \mathrm{M}$ retinaldehyde in the presence or absence of $2 \mathrm{mM} \mathrm{NAD}^{+}$for 30 seconds. Tested inhibitors included WIN18,446 and hydralazine (final concentration $250 \mu \mathrm{M})$. Control groups contained no inhibitor. Samples were processed with the hexane extraction method, and the percentage of control activity was calculated. Incubations were also performed with $1 \mu \mathrm{M}$ retinaldehyde as a substrate to test the impact of substrate concentration on enzyme contribution. Final concentrations of WIN18,446 and hydralazine were $500 \mu \mathrm{M}$ in these experiments. Samples were processed with the ACN precipitation method.

Quantification of AOX and ALDH1A1 in HLS9 Fractions Using LC-MS/ MS. AOX and ALDH1A1 protein concentrations in HLS9 were measured based on previously published protocols with minor modifications (Arnold et al., 2016). Stable isotope-labeled peptides (SIL-peptides) were ordered from Thermo Fisher Scientific and used as IS for AOX and ALDH1A1 quantification (Table 1). SIL-peptides of AOX and ALDH1A1 were labeled with $\left[{ }^{13} \mathrm{C}_{6}^{15} \mathrm{~N}_{2}\right]$ arginine and $\left[{ }^{13} \mathrm{C}_{6}^{15} \mathrm{~N}_{2}\right]$ lysine, respectively.

Mouse liver S9 fractions were used as blank matrix (Arnold et al., 2016) and diluted to $0.5 \mathrm{mg} \mathrm{ml}^{-1}$ with $100 \mathrm{mM}$ ammonium bicarbonate buffer ( $\mathrm{pH} \mathrm{7.8)}$. Various amounts of purified recombinant human AOX (0-4 pmol) and ALDH1A1 (0-10 pmol) were spiked into the diluted mouse liver S9 fractions (20 $\mu \mathrm{l}$ per sample) to make standard curve samples as described previously (Arnold et al., 2016). HLS9 fractions $(10 \mu \mathrm{g}, 0.5 \mathrm{mg} / \mathrm{ml})$ and standard curve samples were first incubated with $4 \mu \mathrm{l}$ of $100 \mathrm{mM}$ dithiothreitol and $10 \mu \mathrm{l}$ of $100 \mathrm{mM}$ ammonium bicarbonate buffer $(\mathrm{pH}$ 7.8) for 20 minutes at room temperature. After $5 \mu \mathrm{l}$ of $10 \%$ sodium deoxycholate was added, samples were incubated at $95^{\circ} \mathrm{C}$ for 5 minutes, and then $4 \mu \mathrm{l}$ of $200 \mathrm{mM}$ iodoacetamide was added, and the samples were incubated at room temperature for 20 minutes. The protein was digested with trypsin at $37^{\circ} \mathrm{C}$ for 15 hours at a $1: 25$ trypsin/protein (w/w) ratio. Trypsin digestion was stopped by the addition of $20 \mu \mathrm{l}$ ice-cold ACN containing $8 \%$ trifluoroacetic acid and internal standards (50 nM SIL-peptide for AOX and $100 \mathrm{nM}$ for ALDH1A1). Samples were centrifuged at $18,000 \mathrm{~g}$ at $4{ }^{\circ} \mathrm{C}$ for 30 minutes, and supernatant was collected for LC-MS/MS analysis.

AOX and ALDH1A1 were quantified via measurement of the signature peptides (Table 1) using an AB Sciex 5500 QTrap quadrupole linear ion trap mass spectrometer coupled with an Agilent 1290 HPLC and an Aeris peptide XB-C18 column $(50 \times 2.1 \mathrm{~mm} ; 1.7-\mu \mathrm{m}$ particle size $)$. The MS parameters used are listed in Table 1. MS transitions for signature peptides of ALDH1A2 and ALDH1A3 were also monitored. Other MS parameters and the chromatographic conditions were as described previously (Arnold et al., 2016). The ratio of signature peptide peak area to SIL IS peptide area was used to construct standard curves and calculate AOX and ALDH1A1 concentrations in HLS9 fractions. The correlation between the protein expression levels and the atRA formation velocity was analyzed by first log-transforming the data and then testing the correlation via Pearson correlation. All measurements were performed in duplicates on three separate days.

Predictions of atRA Formation Velocity and Intrinsic Clearance of Retinaldehyde in HLS9, and the Relative Contribution of AOX and ALDH1A1 to atRA Formation. The intrinsic clearance $\left(\mathrm{CL}_{\mathrm{int}}\right)$ of atRA formation from retinaldehyde was calculated using eq. 2 :

$$
C L_{\text {int }}=\frac{V_{\max }}{K_{m}}
$$


TABLE 1

Peptide sequences and MS parameters for AOX and ALDH1A signature peptides selected for protein quantification using LC-MS/MS

Labeled amino acids in the SIL-peptides are shown as italicized letters. SIL-peptides of AOX and ALDH1A1 were labeled with $\left[{ }^{13} \mathrm{C}_{6}^{15} \mathrm{~N}_{2}\right]$ arginine and $\left[{ }^{13} \mathrm{C}_{6}^{15} \mathrm{~N}_{2}\right]$ lysine, respectively. ALDH1A2 and ALDH1A3 were not detected in any HLS9 samples used in this study.

\begin{tabular}{lccrr}
\hline & Peptide & Precursor & Fragment Ion $(\mathrm{m} / \mathrm{z})$ & DP $(\mathrm{V})$ \\
\hline \multirow{2}{*}{ AOX } & VFFGEGDGIIR & 605.3 & $963.5,816.4$ & 80 \\
& VFFGEGDGIIR & 610.3 & $973.5,826.4$ & 17 \\
ALDH1A1 & ANNTFYGLSAGVFTK & 795.4 & $1042.6,879.5$ & 17 \\
& ANNTFYGLSAGVFT & 799.4 & $1050.6,887.5$ & 120 \\
ALDH1A2 & ILELIQSGVAEGAK & 714.4 & $846.4,959.5$ & 120 \\
ALDH1A3 & EEIFGPVQPILK & 685.4 & $851.5,794.5$ & 120 \\
\hline
\end{tabular}

$\mathrm{CE}$, collision energy; DP, declustering potential; V, voltage.

To scale the activity from the recombinant enzymes to HLS9, intersystem extrapolation factor (ISEF) was calculated using eq. 3:

$$
I S E F=\frac{C L_{\text {int }, \text { pooled liver } S 9}}{C L_{\text {int,recombinant }} \times[\text { enzyme }]}
$$

in which $C L_{\text {int, pooled liver } S 9}$ is the measured intrinsic clearance in the pooled HLS9 sample, and [enzyme] is the enzyme expression measured by LC-MS/

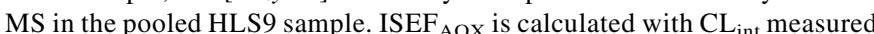
in the absence of $\mathrm{NAD}^{+}$, whereas $\mathrm{ISEF}_{\mathrm{ALDH} 1 \mathrm{~A} 1}$ is calculated with $\mathrm{CL}_{\text {int }}$ measured in the presence of $\mathrm{NAD}^{+}$minus the $\mathrm{CL}_{\text {int }}$ measured in the absence of NAD ${ }^{+}$

The atRA formation velocity in individual HLS9 samples was predicted based on the measured AOX and ALDH1A1 expression levels and the kinetics of atRA formation by recombinant enzymes using eq. 4 :

$$
v_{\text {enzyme }}=\frac{I S E F \times[\text { enzyme }] \times k_{\text {cat }} \times[S]}{K_{m}+[S]}
$$

in which $v_{\text {enzyme }}$ is the predicted atRA formation velocity by a particular enzyme, [enzyme] is the enzyme expression measured in individual HLS9 samples prepared in this study, and $[S]$ is the total substrate concentration. The average fold error (afe) of predictions of atRA formation velocity in three HLS9 samples from individual donors was calculated using eq. 5:

$$
\text { afe }=10^{\frac{1}{n} \sum \log \frac{v_{\text {predicted }}}{v_{\text {observed }}}}
$$

in which $v_{\text {predicted }}$ and $v_{\text {observed }}$ are the predicted and observed atRA formation velocities of the individual HLS9 samples with $1 \mu \mathrm{M}$ retinaldehyde as substrate. The afe values ranging from 0.5 to 1.5 were considered acceptable.

The predicted fraction metabolized by a particular enzyme $\left(f_{m}\right)$ was calculated using eq. 6 :

$$
f_{m, \text { predicted }}=\frac{v_{\text {enzyme }}}{v_{\text {total }}}
$$

in which $v_{\text {total }}$ is the total at RA formation velocity $\left(v_{\text {total }}=\mathrm{v}_{\mathrm{ALDH} 1 \mathrm{~A} 1}+\mathrm{v}_{\mathrm{AOX}}\right)$, and $v_{\text {enzyme }}$ is calculated from eq. 4 , in which [enzyme] is the average value of the enzyme expression measured in three HLS9 samples from individual donors.

The percent inhibition (\%inhibition) of atRA formation in HLS9 caused by CRBP1 was predicted using eq. 7:

$$
\% \text { inhibition }=\text { inhibition }_{A O X} \times f_{m, A O X}+\% \text { inhibition }_{A L D H 1 A 1} \times f_{m, A L D H 1 A 1}
$$

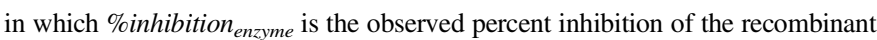
enzyme activity caused by CRBP1. Predicted $\mathrm{f}_{\mathrm{m}}$ values by AOX and ALDH1A1 in the presence of CRBP1 ( $\mathrm{cf}_{\mathrm{m} \text {,enzyme }}$ ) were calculated using eq. 8:

$$
f_{m, \text { enzyme }}=\frac{\text { \%inhibition }_{\text {enzyme }} \times f_{m, \text { enzyme }}}{{\text { \% } \text { inhibition }_{A O X}} \times f_{m, A O X}+\% \text { inhibition }_{A L D H 1 A 1} \times f_{m, A L D H 1 A 1}}
$$

In both eqs. 7 and $8, f_{\text {m,enzyme }}$ indicates the observed relative contribution of a particular enzyme to atRA formation.

\section{Results}

Kinetics of atRA Formation by AOX and ALDH1A1 and Inhibition by Raloxifene, Hydralazine, and WIN18,446. Recombinant human AOX oxidized retinaldehyde to yield atRA (Fig. 1A) with a $\mathrm{K}_{\mathrm{m}}$ of $1.5 \pm 0.4 \mu \mathrm{M}$ and $\mathrm{k}_{\text {cat }}$ of $3.6 \pm 2.0$ minute $^{-1}$ (mean \pm S.D., $n=3$ ), resulting in a $\mathrm{CL}_{\text {int }}$ of $2.6 \pm 1.5 \mu$ minute $^{-1} \mathrm{pmol}^{-1}$. In comparison, the $\mathrm{K}_{\mathrm{m}}$ of retinaldehyde oxidation with ALDH1A1 was $0.25 \mu \mathrm{M}$, and $\mathrm{k}_{\mathrm{cat}}$ was 0.38 minute ${ }^{-1}$, resulting in a $\mathrm{CL}_{\mathrm{int}}$ of $1.5 \mu 1$ minute $^{-1} \mathrm{pmol}^{-1}$ (Supplemental Fig. 1). AOX inhibitors raloxifene and hydralazine both inhibited atRA formation by recombinant $\mathrm{AOX}$, with $\mathrm{IC}_{50}$ values $<1$ $\mu \mathrm{M}$ (Fig. 1, E and F). The $\mathrm{IC}_{50}$ value of hydralazine was about 3-fold higher than that of raloxifene (Table 2). WIN18,446 did not inhibit AOX activity at inhibitor concentrations up to $500 \mu \mathrm{M}$, whereas both AOX inhibitors, raloxifene and hydralazine, exhibited inhibitory effects on recombinant ALDH1A1, although at higher inhibitor concentrations than those causing AOX inhibition (Fig. 1, B-D). Based on these data, WIN18,446 is a selective inhibitor of ALDH1A1 at concentrations up to $100 \mu \mathrm{M}$. The difference in $\mathrm{IC}_{50}$ values between AOX and ALDH1A1 for raloxifene was only 10 -fold, suggesting raloxifene is not sufficiently selective as an inhibitor of AOX. In contrast, hydralazine can be used as a selective and potent inhibitor of AOX based on the $>4000$-fold difference in the $\mathrm{IC}_{50}$ values between AOX and ALDH1A1 (Table 2).

atRA Formation in HLS9. The potential enzymes forming atRA in human liver all use different cofactors, and therefore, cofactor dependence can be used to differentiate the enzyme contributions to atRA formation. In HLS9, atRA formation was observed in the absence of cofactors $\left(\mathrm{NAD}^{+} / \mathrm{NADP}^{+} / \mathrm{NADPH}\right.$; Fig. $\left.2 \mathrm{~A}\right)$, with a substrate concentration of $2 \mu \mathrm{M}$. A linear Eadie-Hofstee plot (Fig. 2B) indicated that a single enzyme in HLS9 contributed to atRA formation in the absence of cofactors. $\mathrm{V}_{\max }$ obtained by fitting the single-enzyme MichaelisMenten equation to the data was $646 \pm 132 \mathrm{pmol}$ minute ${ }^{-1} \mathrm{mg}^{-1} \mathrm{~S} 9$ protein, and $\mathrm{K}_{\mathrm{m}}$ of retinaldehyde was $1.4 \pm 0.9 \mu \mathrm{M}$ (mean \pm S.D., $n=3$ ), similar to the $\mathrm{K}_{\mathrm{m}}$ value measured with recombinant AOX. The $\mathrm{CL}_{\text {int }}$ for $a t \mathrm{RA}$ formation was $615 \pm 397 \mu \mathrm{l}$ minute ${ }^{-1} \mathrm{mg}^{-1} \mathrm{~S} 9$ protein (mean \pm S.D., $n=3$ ). Based on the fact that this activity did not require a cofactor, the enzyme responsible for this activity is likely AOX.

The addition of NADPH and NADH to the incubations did not result in any increase in atRA formation velocity in comparison to incubations without a cofactor, indicating that cytochrome P450 and NADHdependent enzymes play a negligible role in retinaldehyde oxidation in human liver (Fig. 2A). In the presence of $\mathrm{NAD}^{+}$, the velocity of atRA formation measured with $2 \mu \mathrm{M}$ retinaldehyde was about 1.8 -fold higher than that measured in the absence of $\mathrm{NAD}^{+}$. The Eadie-Hofstee plot (Fig. 2C) indicated that two enzymes in HLS9 fractions were responsible for $a t \mathrm{RA}$ synthesis in the presence of $\mathrm{NAD}^{+}$. The low-affinity enzyme was assumed to be AOX with the kinetic parameters described above. As the two-enzyme Michaelis-Menten model was fitted to the data, the 

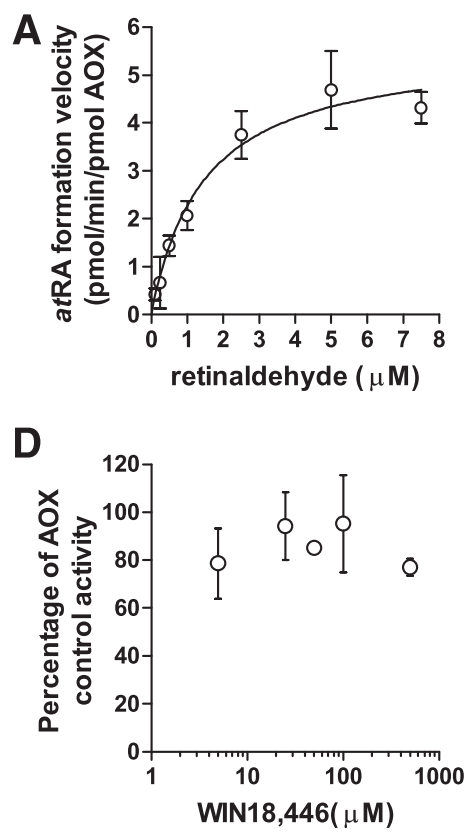

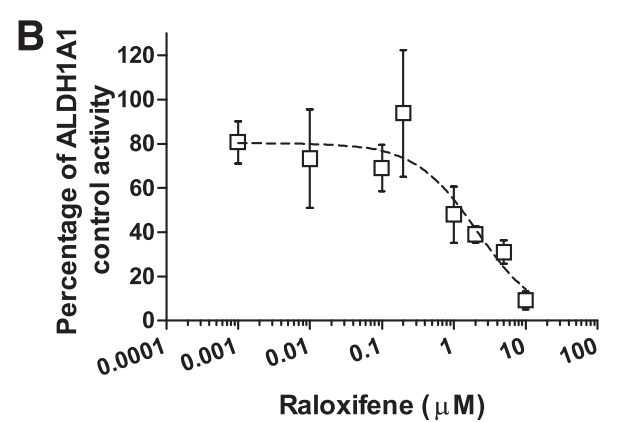

E

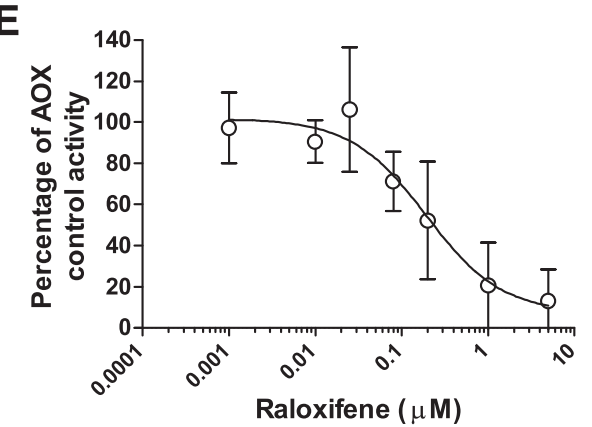

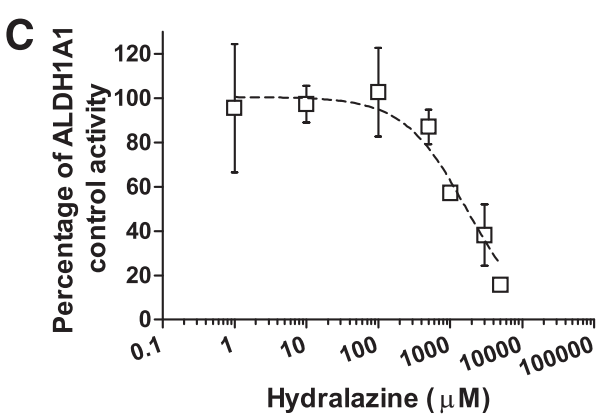

F

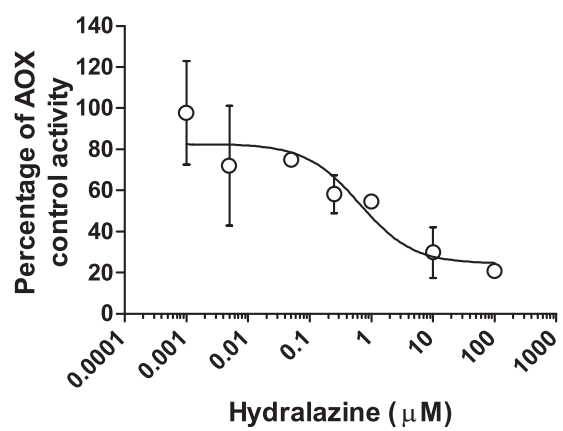

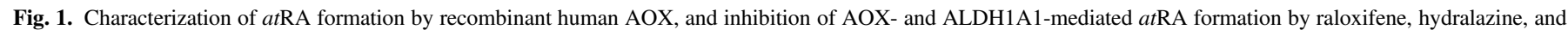

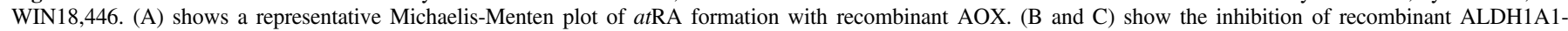

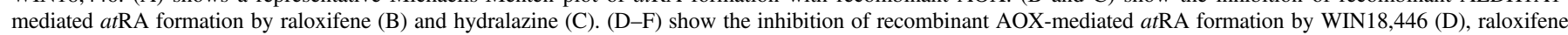

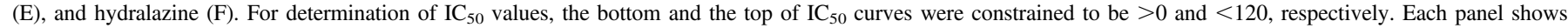

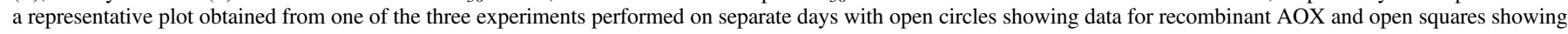
data for recombinant ALDH1A1. Data points and error bars represent mean and S.D. of triplicates within the experiment.

high-affinity enzyme $\mathrm{V}_{\max }$ and $\mathrm{K}_{\mathrm{m}}$ values were $518 \pm 288 \mathrm{pmol}$ minute $^{-1} \mathrm{mg}^{-1} \mathrm{~S} 9$ protein and $0.38 \pm 0.13 \mu \mathrm{M}$ (mean \pm S.D. $n=3$ ), respectively. The $\mathrm{CL}_{\text {int }}$ of the high-affinity enzyme was $1299 \pm 370 \mu \mathrm{l}$ minute ${ }^{-1} \mathrm{mg}^{-1} \mathrm{~S} 9$ protein (mean \pm S.D., $n=3$ ), and the overall $\mathrm{CL}_{\text {int }}$ was $1914 \mu \mathrm{l} \mathrm{minute}^{-1} \mathrm{mg}^{-1} \mathrm{~S} 9$ protein. Based on the requirement of $\mathrm{NAD}^{+}$for the activity of the observed second enzyme, this activity is likely ALDH1A1. Taken together, these data strongly support that both ALDH1A1 and AOX contribute to atRA biosynthesis in human liver.

Predicted Contribution of AOX and ALDH1A1 to atRA Formation in HLS9. The signature peptide of AOX for quantification was selected based on the MS signal intensity and peptide stability in matrix (Supplemental Fig. 2). The selected human AOX and ALDH1A1 quantification peptides were observed in HLS9 but not in mouse liver S9, demonstrating the specificity of these peptides (Fig. 3, A and B). The expression level of ALDH1A1 in HLS9 (156-285 pmol mg S9 protein $^{-1}$ ) was on average 13-fold higher than the expression of AOX (9.4-24 pmol mg S9 protein $^{-1}$ ) (Fig. 3C). No expression of ALDH1A2 or ALDH1A3 was detected in the HLS9 (data not shown).

Using $\mathrm{CL}_{\text {int }}$ obtained in the pooled HLS9 and recombinant enzymes, $\mathrm{ISEF}_{\mathrm{AOX}}$ and $\mathrm{ISEF}_{\mathrm{ALDH1} 1 \mathrm{~A} 1}$ were calculated to be 25 and 6, respectively.

TABLE 2

$\mathrm{IC}_{50}$ values of raloxifene, hydralazine, and WIN18,446 measured against recombinant AOX and ALDH1A1 enzymes (mean \pm S.D., $n=3$ )

The selectivity index was calculated by dividing the $\mathrm{IC}_{50}$ value of the nontarget enzyme by the $\mathrm{IC}_{50}$ value of the target enzyme.

\begin{tabular}{lccc}
\hline & AOX & ALDH1A1 & Selectivity index \\
\hline Raloxifene $(\mu \mathrm{M})$ & $0.15 \pm 0.05$ & $1.54 \pm 0.54$ & 10.3 \\
Hydralazine $(\mu \mathrm{M})$ & $0.42 \pm 0.21$ & $1840 \pm 690$ & 4381 \\
WIN18,446 $(\mu \mathrm{M})$ & $>500$ & $0.102^{a}$ & $>4900$ \\
\hline
\end{tabular}

${ }^{a}$ The $\mathrm{IC}_{50}$ value is from Arnold et al. (2015b).
The predicted velocity of $a t$ RA formation mediated by AOX in the three individual livers ranged from 586 to 846 pmol minute $\mathrm{mg}^{-1} \mathrm{~S} 9$, and the predicted total velocity including AOX and ALDH1A1 ranged from 943 to 1366 pmol minute ${ }^{-1} \mathrm{mg}^{-1} \mathrm{~S} 9$. When compared with the observed formation velocities in the three individual livers, AOX-mediated formation of atRA had an afe of 1.35 , and the total velocity had an afe of 0.71 , both within 2-fold of the observed velocities measured without (371-655 pmol minute ${ }^{-1} \mathrm{mg}^{-1} \mathrm{~S} 9$ ) and with (1377-1861 pmol minute ${ }^{-1} \mathrm{mg}^{-1} \mathrm{~S} 9$; Fig. 3) $\mathrm{NAD}^{+}$. With $\mathrm{NAD}^{+}$, at RA formation velocity measured with $1 \mu \mathrm{M}$ retinaldehyde positively correlated with the enzyme expression of ALDH1A1 $(r=0.99 ; P=0.011)$ and AOX $(r=$ 0.98; $P=0.022$ ) in HLS9 (Fig. 3, D and E). However, the AOX expression did not show a correlation with atRA formation velocity measured in the absence of $\mathrm{NAD}^{+}(r=-0.80 ; P=0.20$; Fig. 3E), possibly suggesting that not all MS-quantified AOX in the liver is catalytically active (Fu et al., 2013). The expression of ALDH1A1 showed a weak correlation with the expression of $\operatorname{AOX}(r=0.94 ; P=0.065$; Fig 3C).

The fraction of atRA formation by AOX and ALDH1A1 ( $\left.f_{m}\right)$ is expected to vary with retinaldehyde concentration because of the differences in the $\mathrm{K}_{\mathrm{m}}$ values for the two enzymes. Based on the AOX and ALDH1A1 expression and atRA formation kinetics, the $\mathrm{f}_{\mathrm{m}, \mathrm{AOX}}$ was predicted to increase from 0.36 to 0.73 , and $\mathrm{f}_{\mathrm{m}, \mathrm{ALDH} 1 \mathrm{~A} 1}$ was predicted to decrease from 0.64 to 0.27 as retinaldehyde concentration increased from low nanomolar concentrations to saturating concentrations $(5 \mu \mathrm{M})$ (Fig. 3F). As such, determination of the relative importance of each enzyme to atRA formation in human liver depends on substrate concentrations and should be assessed at biologically relevant concentrations of retinaldehyde.

Observed Relative Contribution of AOX and ALDH1A1 to atRA Formation in HLS9. To determine the quantitative contributions of ALDH1A1 and AOX to atRA formation in human livers, inhibition of atRA formation in human liver by hydralazine (selective AOX inhibitor) 

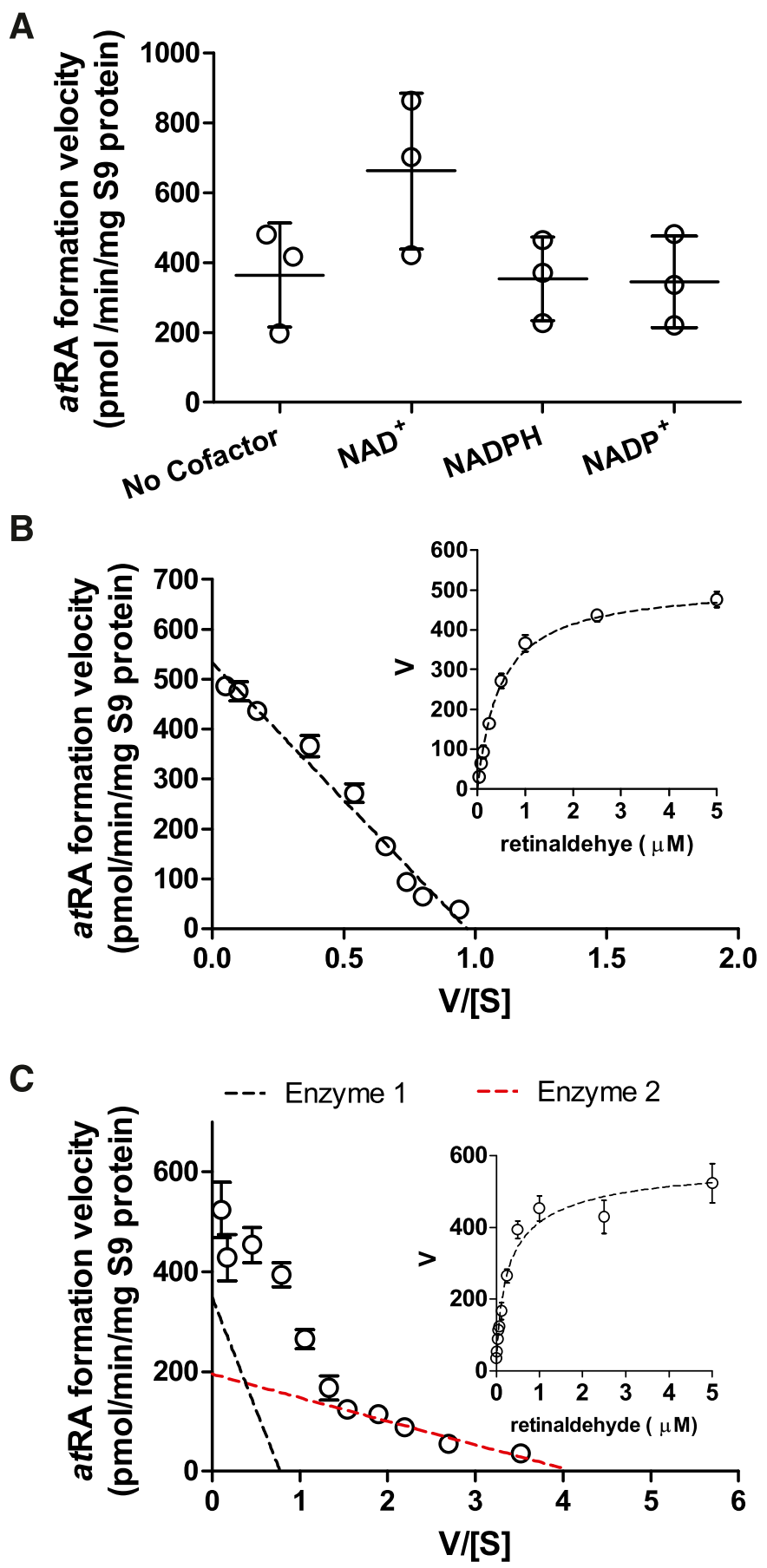

Fig. 2. Characterization of atRA formation in human liver. (A) shows the dependence of $a t$ RA formation on different cofactors in pooled HLS9. Each data point represents a mean of triplicate assays performed on separate days. Horizontal lines and error bars represent mean and S.D. of the measurements over the different days. The retinaldehyde concentration used in the incubations was $2 \mu \mathrm{M}$. Nonenzymatic atRA formation was subtracted from the total atRA formation to calculate the velocity of enzymatic atRA formation in each group. (B and C) show retinaldehyde concentration-dependent atRA formation by HLS9 in the absence (B) and presence $(\mathrm{C})$ of $\mathrm{NAD}^{+}$. Representative Eadie-Hofstee plots of atRA formation by HLS9 are shown, with the Michaelis-Menten plots of atRA formation shown in insets. Each Eadie-Hofstee plot is a representative plot obtained from one of the three experiments performed on separate days. Individual data points shown as open circles and error bars represent mean and S.D. of triplicates within the day. The inset in (B) shows the fit of a single-enzyme Michaelis-Menten equation to the data, and the inset in (C) shows the fit of a two-enzyme Michaelis-Menten equation to the data as described in Materials and Methods. [S], substrate concetration; v, velocity. and WIN18,446 (selective ALDH1A1 inhibitor) was characterized. Inhibitor concentrations used in HLS9 incubations were first tested with purified recombinant enzymes to confirm selectivity and efficacy of inhibition. At their selected concentrations, hydralazine and WIN18,446 caused $>95 \%$ inhibition of their target enzymes, AOX and ALDH1A1, without inhibiting the nontargeted enzymes (Fig. 4, A and B). In HLS9 incubations without $\mathrm{NAD}^{+}$cofactor, hydralazine inhibited $>95 \%$ of atRA formation, whereas WIN18,446 did not lead to any significant inhibition (Fig. 4, C and D). These data confirm that AOX is the enzyme responsible for the non-NAD ${ }^{+}$-dependent formation of atRA. In the presence of $\mathrm{NAD}^{+}$, hydralazine inhibited only $24 \% \pm 6 \%$ (mean \pm S.D., $n=4$ ) of $a t$ RA formation in HLS9 with a substrate concentration of $0.2 \mu \mathrm{M}$, whereas WIN18,446 inhibited $81 \% \pm 6 \%($ mean \pm S.D., $n=4)$ of atRA formation (Fig. 4E). The predicted $\mathrm{f}_{\mathrm{m}}$ of ALDH1A1 (0.53) underpredicted ALDH1A1 contribution to atRA formation in HLS9 at $0.2 \mu \mathrm{M}$ retinaldehyde, whereas that of AOX (0.47) was overestimated (Fig. 3F). With $1 \mu \mathrm{M}$ retinaldehyde as a substrate, hydralazine and WIN18,446 inhibited $47 \% \pm 15 \%$ and $56 \% \pm 11 \%$ (mean \pm S.D., $n=4$ ) of the total atRA formation activity (Fig. 4F), respectively, demonstrating the decreased contribution of ALDH1A1 to atRA formation at higher substrate concentrations. The observed percent inhibition at $1 \mu \mathrm{M}$ retinaldehyde was higher than the predicted $\mathrm{f}_{\mathrm{m}}$ of ALDH1A1 (0.38) and lower than the predicted $f_{m}$ of AOX (0.62) (Fig. 3F). The combination of hydralazine and WIN18,446 abolished $>95 \%$ of atRA formation in HLS9 samples when incubated in the presence of $\mathrm{NAD}^{+}$, suggesting that AOX and ALDH1A1 are the only enzymes contributing to atRA formation in HLS9.

Effects of CRBP1 on AOX and ALDH1A1 Activity. To determine whether binding to CRBP1 affects the formation of atRA by AOX or ALDH1A1 and their relative importance in hepatic atRA formation, atRA formation velocity was measured with recombinant enzymes and HLS9 using holo-CRBP1 as the substrate. As shown in Fig. 5A, in the presence of CRBP1, the formation of atRA by AOX and ALDH1A1 decreased about $85 \%$ and $55 \%$ in comparison with control incubations that contained no CRBP1. As AOX and ALDH1A1 contribute about $20 \%$ and $80 \%$ to atRA formation in HLS9 in the absence of CRBP1, the activity of atRA formation in HLS9 was predicted to decrease by $61 \%$ in the presence of CRBP1. The $\mathrm{f}_{\mathrm{m}}$ values by AOX and ALDH1A1 were estimated to be 0.08 and 0.92 , respectively, in the presence of CRBP1 (Fig. 5B). The decrease in atRA formation caused by CRBP1 was tested in HLS9, and the addition of CRBP1 decreased atRA formation by $63 \%$ when compared with the no-CRBP control (Fig. 5A), a level of inhibition consistent with predictions.

\section{Discussion}

To date, the majority of the knowledge regarding the role of specific at RA biosynthesis enzymes is derived from studies in developmental biology and altered retinoid signaling during embryonic development. However, the biologic importance of vitamin A metabolizing enzymes defined during embryonic development does not always translate to postnatal life. For example, the embryonic knockout of Aldh1a2 leads to embryonic death in mice (Niederreither et al., 2002), but neither tamoxifen-induced postnatal global knockout of Aldh1a2 or germ cell-specific deletion of Aldh1a2 caused any abnormal phenotype (Beedle et al., 2019). A similar discrepancy was observed with atRA hydroxylase Cyp26a1. Cyp26a1 knockout is embryonically lethal, but postnatal knockout has no major effects on mouse health (Zhong et al., 2019a). Although knockout mouse models have allowed considerable progress in defining the enzymology of vitamin A and retinoid homeostasis, knowledge of the role of specific enzymes in atRA biosynthesis in human tissues is still limited. This includes limited knowledge of the 


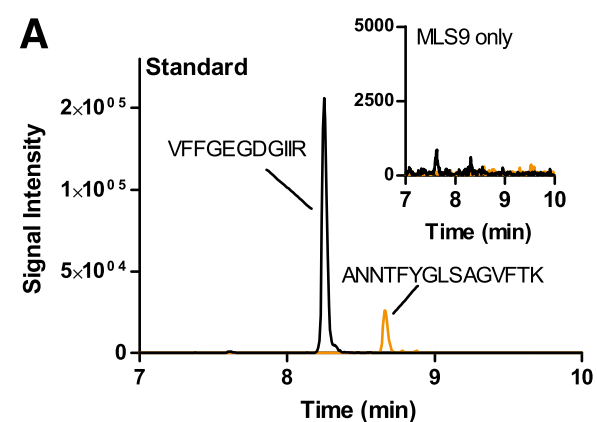

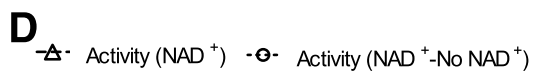

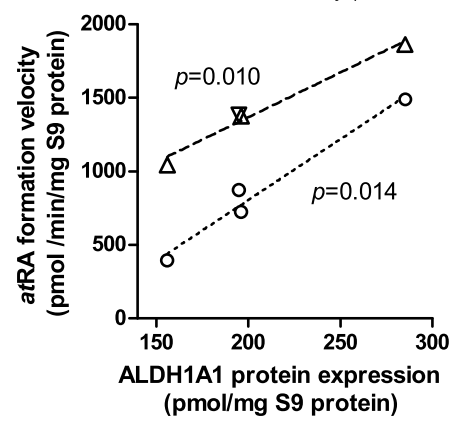

B

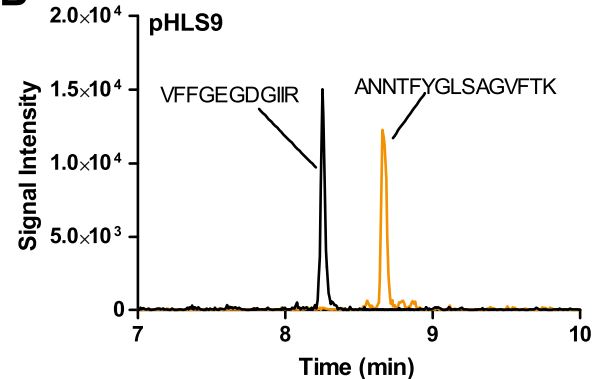

$\mathbf{F}$

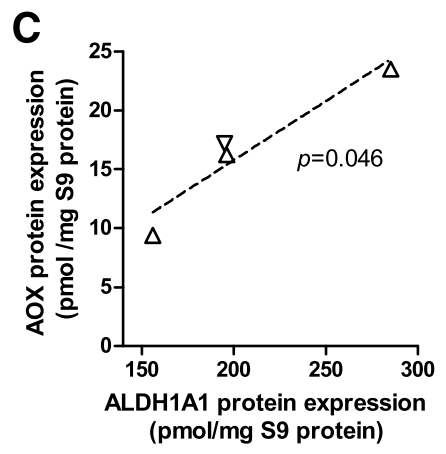

$E$

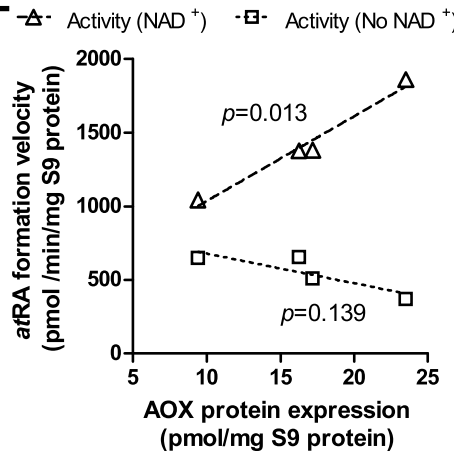

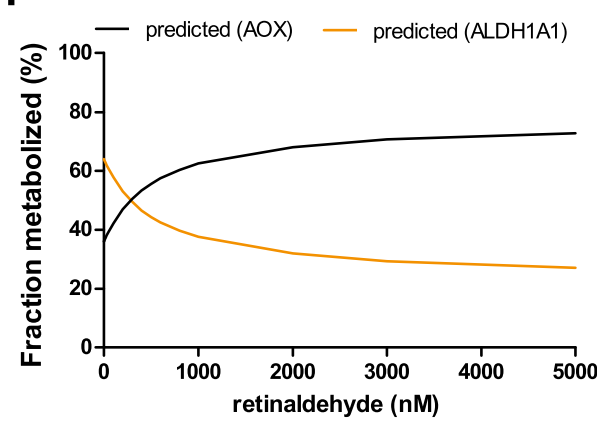

Fig. 3. Characterization of expression of AOX and ALDH1A1 and their predicted contribution to atRA formation in human liver. (A and B) show the LC-MS/MS measurement of AOX and ALDH1A1 protein expression. The quantified MS/MS transitions of AOX $(\mathrm{m} / \mathrm{z} 605.3>963.5)$ and ALDH1A1 (m/z 795.4 > 879.5) signature peptides are shown in black and orange, respectively. (A) shows the LC-MS/MS chromatogram of a sample of mouse liver S9 (MLS9) fraction spiked with 1 pmol purified recombinant human AOX and $2.5 \mathrm{pmol}$ purified recombinant human ALDH1A1 (standard sample). The inset in (A) shows MLS9 without adding any recombinant human AOX and ALDH1A1. (B) shows a representative chromatogram of pooled human liver S9 fraction and detection of AOX and ALDH1A1 in human liver. (C) shows the correlation between AOX and ALDH1A1 protein expression, and (D and E) show the correlation between the ALDH1A1 (D) and AOX (E) protein expression and the observed atRA formation velocity measured at $1 \mu \mathrm{M}$ retinaldehyde. "Activity $\left(\mathrm{NAD}^{+}\right)$" indicates the total velocity measured in the presence of $\mathrm{NAD}^{+}$that reflects contribution by both AOX and ALDH1A1; "Activity (No NAD ${ }^{+}$)" indicates the velocity measured in the absence of NAD" reflecting only AOX activity; Activity (NAD"-No $\left.\mathrm{NAD}^{+}\right)=$Activity $\left(\mathrm{NAD}^{+}\right)$- Activity $\left(\mathrm{No} \mathrm{NAD}^{+}\right)$. Each symbol represents an individual HLS9 sample. Symbols represent the mean values of three individual experiments conducted on separate days in duplicates. The dashed lines show the linear regression between the enzyme expression and atRA formation velocity; $P$ values shown in the panels indicate whether the slope of the corresponding line is significantly different from zero. (F) shows the dependence of predicted ALDH1A1 and AOX contributions to $a t$ RA formation $\left(\mathrm{f}_{\mathrm{m}}\right)$ on retinaldehyde concentrations. The solid lines indicate predicted $\mathrm{f}_{\mathrm{m}}$ of atRA formation by ALDH1A1 (orange) and AOX (black) in HLS9 fractions.

identity of the enzymes synthesizing atRA in the human liver, the main storage organ for vitamin A. The goal of this study was to determine the main enzymes synthesizing atRA in the human liver and test the hypothesis that AOX contributes to atRA biosynthesis in the human liver.

This study unequivocally shows that AOX forms atRA from retinaldehyde and that in human liver ALDH1A1 and AOX contribute to atRA biosynthesis. Recombinant AOX exhibited about 6-fold higher $\mathrm{K}_{\mathrm{m}}$ and 1.6-fold higher $\mathrm{CL}_{\text {int }}$ than $\mathrm{ALDH} 1 \mathrm{~A} 1$ for atRA formation, showing that ALDH1A1 is a high-affinity, low-capacity atRA synthesizing enzyme, whereas AOX is a low-affinity, high-capacity enzyme. According to the human protein atlas data base, AOX protein is expressed in the kidney, bladder, pancreas, endocrine tissues, and reproductive tissues (https://www.proteinatlas.org/ENSG00000138356-AOX1/tissue). This suggests that AOX may contribute to atRA synthesis in the testis, among other tissues. However, studies in healthy mice have shown that AOX activity is not quantitatively significant in the mouse testis (Arnold et al., 2015a) but rather that AOX plays a role in testicular atRA synthesis in mice when ALDH1A activity is impaired (Beedle et al., 2019). This is in agreement with the findings in the human testis showing that ALDH1A1 and ALDH1A2 are responsible for $>95 \%$ of $a t$ RA formation in this tissue (Arnold et al., 2015). In contrast to the testis, AOX appears to contribute about $50 \%$ of atRA biosynthesis in mouse liver (Arnold et al., 2015a). This suggests a tissue-specific role of AOX that likely depends on the expression levels of AOX and the complement of ALDH1A enzymes expressed in the different tissues. The results of this study support a similar role of AOX in atRA biosynthesis in human liver as in the mouse liver, with AOX contributing between $33 \%$ and $70 \%$ of atRA biosynthesis depending on retinaldehyde concentration. The reported total concentrations of retinaldehyde in the liver and adipose are 100-200 pmol/g ( $150 \mathrm{nM}$ ) (Ziouzenkova et al., 2007; Kane et al., 2008). These concentrations are much below the $\mathrm{K}_{\mathrm{m}}$ toward AOX $(1.5 \mu \mathrm{M})$ but similar to the $\mathrm{K}_{\mathrm{m}}$ toward ALDH1A1 $(0.25 \mu \mathrm{M})$. Because of the difference in $\mathrm{K}_{\mathrm{m}}$ values for AOX and ALDH1A1, the predicted and observed $f_{m}$ values of retinaldehyde by AOX show a clear dependence on retinaldehyde concentration within the evaluated range of 20-2,000 nM retinaldehyde. As the concentration of retinaldehyde increases, $f_{m, A O X}$ increases due to the saturation of the high-affinity ALDH1A1. This also suggests that in the case of ALDH1A dysfunction (inhibition, downregulation, or genetic defect) or excess retinoid/vitamin A (saturation of ALDH1A1), AOX plays an important role in regulating hepatic vitamin A homeostasis. The relative contribution of $\mathrm{AOX}(30 \%-70 \%)$ to atRA biosynthesis is supported by the scaling of atRA formation from recombinant enzymes, the quantification of AOX and ALDH1A1 protein expression in the liver, the cofactor dependence of atRA formation, and the inhibition of atRA formation by selective ALDH1A and AOX inhibitors WIN18,446 and hydralazine. These tools developed in the current study allow differentiation of ALDH1A and AOX contributions to atRA formation and can be further applied to other critical retinoid responsive tissues, such as the skin, hematopoietic cells, and adipose tissue, to determine the enzymes contributing to atRA biosynthesis. Such information will be useful in predicting how inhibition or genetic variability in AOX and ALDH1A enzymes will affect retinoid homeostasis and signaling.

In tissues that contribute to vitamin A homeostasis, CRBP1 is expressed, and retinoids are believed to be bound to retinoid binding 
A

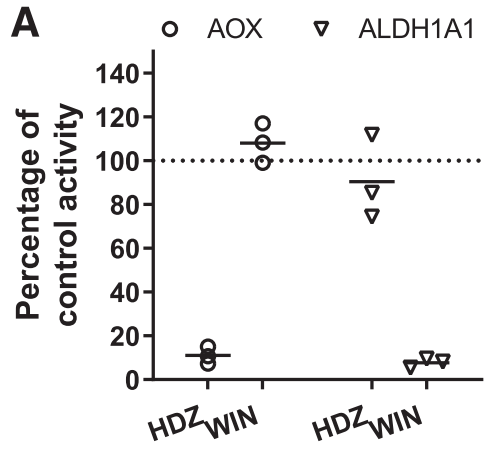

C

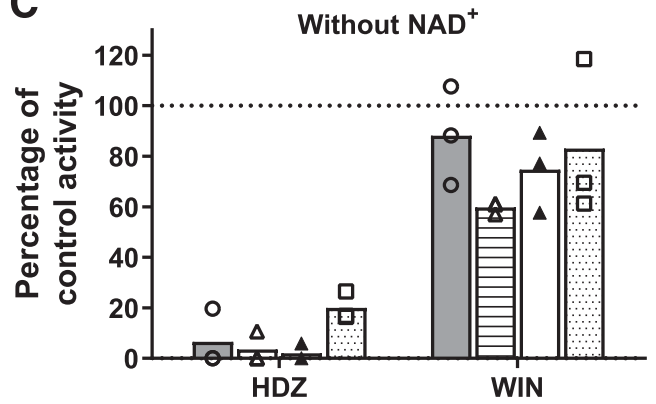

$\mathbf{E}$

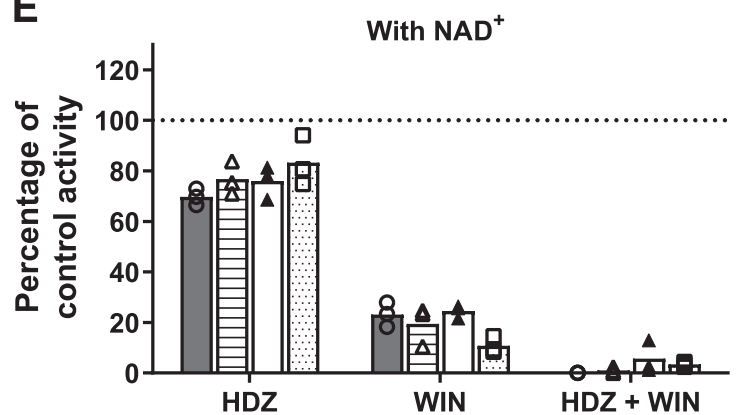

B

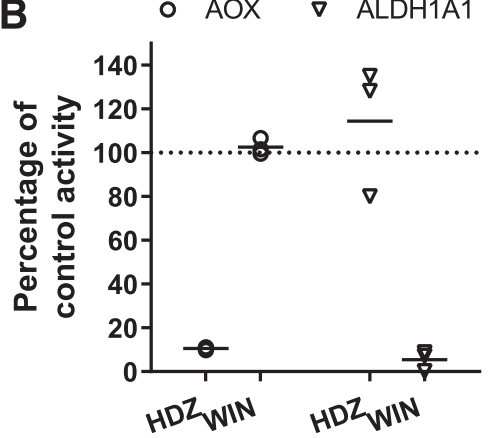

D

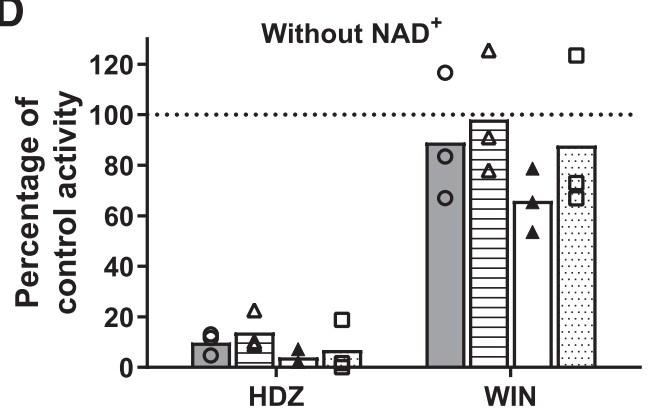

$\mathbf{F}$

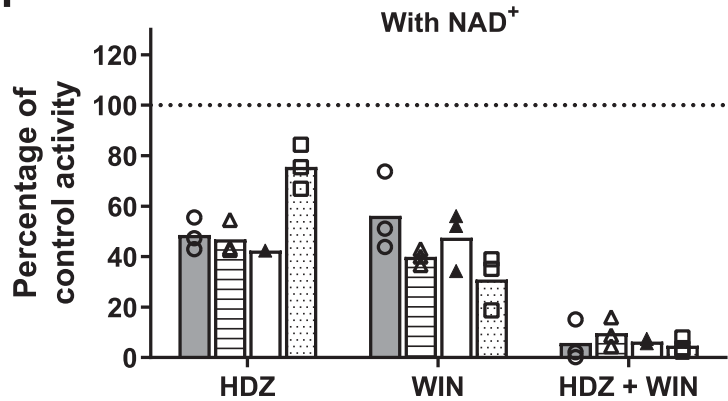

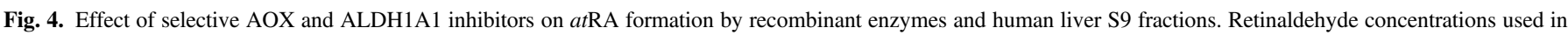

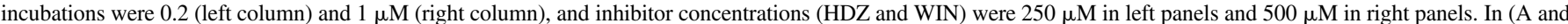

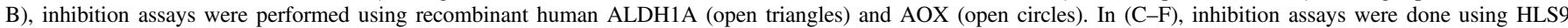

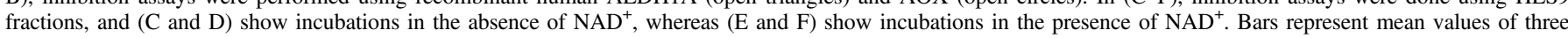

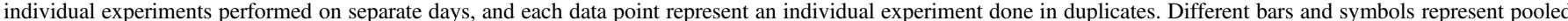

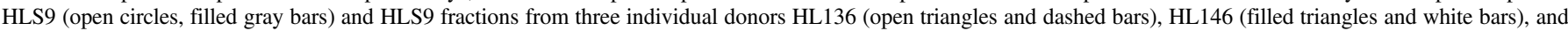
HL149 (open squares and dotted bars). HDZ, hydralazine; WIN, WIN18,446.

proteins (Noy, 2000; Napoli, 2016). As such, CRBP1 can impact retinoid metabolism and the enzymology of atRA biosynthesis. The presence of CRBP1 decreased the atRA formation velocity by both ALDH1A1 and AOX. This finding is in agreement with previous demonstration that with CRBP1, the activity of ALDH1A1-mediated atRA formation decreased about $52 \%$ when compared with the activity measured without CRBP1 (Arnold et al., 2015). Similarly, with $0.2 \mu \mathrm{M}$ CRBP1-bound retinaldehyde as a substrate, atRA formation velocity measured in the $\mathrm{E} 2$ fraction (associated with AOX) from soluble extracts of human liver was about $70 \%$ to $80 \%$ lower than that measured without CRBP1 (Ambroziak et al., 1999). However, as shown here, CRBP1 binding decreased atRA formation by both ALDH1A1 and AOX, and therefore the impact of CRBP1 on the $f_{m}$ values by AOX and ALDH1A1 is likely modest. In addition, CRBP1 binding is unlikely to have a significant impact on atRA formation in vivo, as CRABP1 in human liver is expected to be bound by hepatic retinol [1.2-162 $\mu \mathrm{M}$; (Zhong et al., 2019b)], which has a $\mathrm{K}_{\mathrm{d}}$ of $\sim 18.6 \mathrm{nM}$ to CRBP1 compared with $\mathrm{K}_{\mathrm{d}}$ of retinaldehyde $\sim 44 \mathrm{nM}$; (Ambroziak et al., 1999; Silvaroli et al., 2016).
The results of this study show that the human liver possesses a high at RA biosynthesis capacity. The observed atRA formation velocity in the HLS9 observed here (1043-1861 pmol minute ${ }^{-1} \mathrm{mg}^{-1} \mathrm{~S} 9$ protein) is 31- to 56-fold higher than the observed atRA formation velocity in human testis (33.3 pmol minute ${ }^{-1} \mathrm{mg}^{-1} \mathrm{~S} 10$ protein at $1 \mu \mathrm{M}$ retinaldehyde) (Arnold et al., 2015). This difference in atRA formation velocities is comparable to the difference between human testicular $(4.3 \pm$ $0.5 \mathrm{pmol} \mathrm{g}^{-1}$ testis) and hepatic tissue atRA concentrations (14 $580 \mathrm{pmol} \mathrm{g}^{-1}$, median 43 pmol g $^{-1}$ liver) (Arnold et al., 2015; Zhong et al., 2019b). This finding supports the previous report in human testis that variability in tissue atRA formation kinetics could be used to predict the variability in tissue atRA concentrations (Arnold et al., 2015). The velocity of atRA formation in HLS9 was successfully predicted at a single concentration of retinaldehyde in this study when AOX and ALDH1A1 protein expression and specific ISEF values were applied to individual donors. As reported in the literature, with xenobiotic substrates of AOX, AOX activity is often poorly scaled from one system to another (e.g., recombinant enzyme to cytosol, in vitro to in vivo), and recombinant 


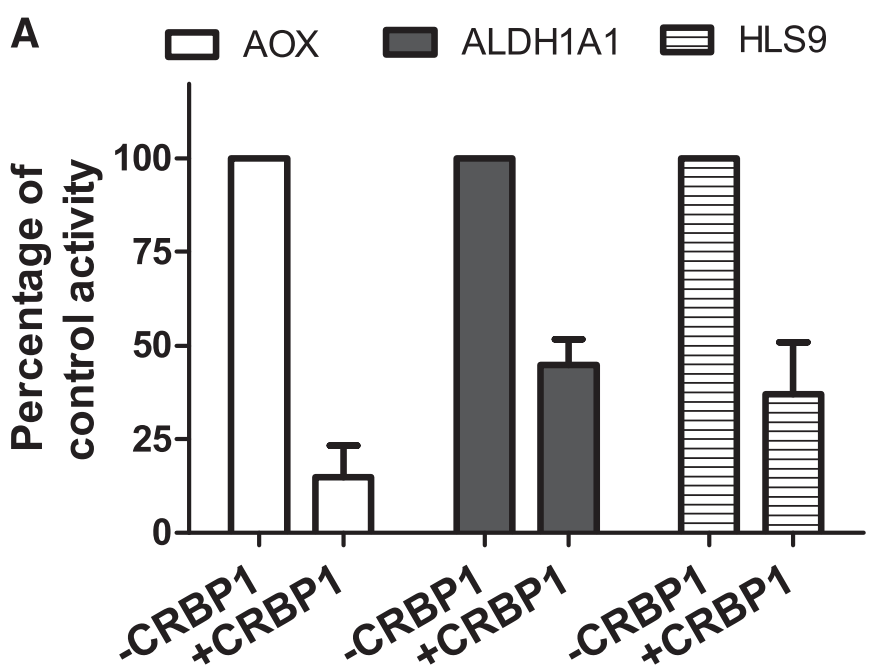

B

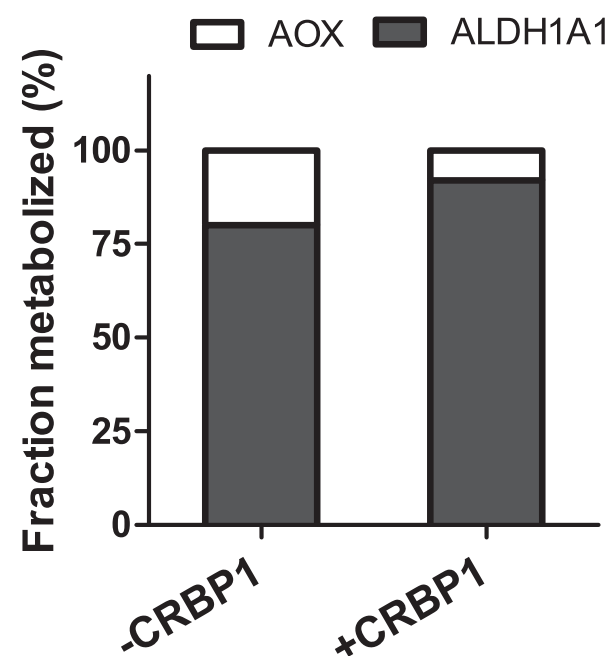

Fig. 5. Effects of CRBP1 on atRA formation by recombinant AOX, ALDH1A1, and human liver S9. (A) shows atRA formation velocity when free retinaldehyde $(-\mathrm{CRBP})$ or holo-CRBP1 (+CRABP) is used as a substrate. The bars represent the mean percent inhibition from three individual experiments conducted on separate days, and error bars represent S.D. (B) shows the predicted fraction of retinaldehyde metabolized by AOX and ALDH1A1 in the presence and absence of CRBP1. The substrate concentration (retinaldehyde or CRBP1-bound retinaldehyde) was $0.2 \mu \mathrm{M}$ in all experiments.

AOX typically underpredicts the activity in native environment (Pryde et al., 2010; Fu et al., 2013), suggesting that atRA biosynthesis may be more efficient by AOX in vivo than predicted from the HLS9 here. This finding was confirmed in the current study, with the data suggesting an ISEF value of 20 for AOX. Surprisingly, ALDH1A1 also had an ISEF value of 6 in this study when previous work in the human testis indicated an ISEF value of approximately 2 for ALDH1A. As ISEF values may vary for different tissues and for different enzymes, these findings emphasize the importance of independent experiments such as selective inhibition studies to determine the relative contributions of individual enzymes to atRA formation.

In conclusion, this study shows that human AOX is responsible for $30 \%-70 \%$ of atRA biosynthesis in human liver. The importance of AOX and ALDH1A1 in atRA biosynthesis and in regulation of atRA signaling is an intriguing intersection between xenobiotic and endogenous compound metabolism. As many AOX inhibitors are therapeutic drugs, the administration of these drugs may affect atRA gradients and signaling in the liver and other tissues. Determining whether AOX inhibition in the liver or in other organs alters atRA concentrations and biosynthesis requires further study. Additionally, reported single nucleotide polymorphisms of human AOX (Hartmann et al., 2012; Hutzler et al., 2014; Foti et al., 2017) may have an impact on in vivo retinaldehyde clearance and tissue $a t$ RA gradients. As such the impact of altered AOX activity on atRA concentrations and vitamin A homeostasis should be considered in preclinical and clinical studies.

\section{Authorship Contributions}

Participated in research design: Zhong, Isoherranen.

Conducted experiments: Zhong, Seaman, Xi, Paragas, Herpoldt.

Contributed new reagents or analytic tools: Paragas, Jones, Herpoldt, King. Performed data analysis: Zhong, Seaman.

Wrote or contributed to the writing of the manuscript: Zhong, Seaman, Paragas, Herpoldt, King, Jones, Isoherranen.

\section{References}

Ambroziak W, Izaguirre G, and Pietruszko R (1999) Metabolism of retinaldehyde and other aldehydes in soluble extracts of human liver and kidney. J Biol Chem 274:33366-33373.

Arnold SL, Kent T, Hogarth CA, Griswold MD, Amory JK, and Isoherranen N (2015a) Pharmacological inhibition of ALDH1A in mice decreases all-trans retinoic acid concentrations in a tissue specific manner. Biochem Pharmacol 95:177-192.

Arnold SL, Kent T, Hogarth CA, Schlatt S, Prasad B, Haenisch M, Walsh T, Muller CH, Griswold $\mathrm{MD}$, Amory JK, et al. (2015b) Importance of ALDH1A enzymes in determining human testicular retinoic acid concentrations. J Lipid Res 56:342-357.

Arnold SL, Stevison F, and Isoherranen N (2016) Impact of sample matrix on accuracy of peptide quantification: assessment of calibrator and internal standard selection and method validation. Anal Chem 88:746-753.

Barr JT, Jones JP, Joswig-Jones CA, and Rock DA (2013) Absolute quantification of aldehyde oxidase protein in human liver using liquid chromatography-tandem mass spectrometry. $\mathrm{Mol}$ Pharm 10:3842-3849.

Beedle MT, Stevison F, Zhong G, Topping T, Hogarth C, Isoherranen N, and Griswold MD (2019) Sources of all-trans retinal oxidation independent of the aldehyde dehydrogenase $1 \mathrm{~A}$ isozymes exist in the postnatal testis. Biol Reprod 100:547-560.

Czuba LC, Zhong G, Yabut KC, and Isoherranen N (2020) Analysis of vitamin A and retinoids in biological matrices. Methods Enzymol 637:309-340.

Fan X, Molotkov A, Manabe S, Donmoyer CM, Deltour L, Foglio MH, Cuenca AE, Blaner WS, Lipton SA, and Duester G (2003) Targeted disruption of Aldh1a1 (Raldh1) provides evidence for a complex mechanism of retinoic acid synthesis in the developing retina. Mol Cell Biol $\mathbf{2 3}$. $4637-4648$.

Foti A, Dorendorf F, and Leimkühler S (2017) A single nucleotide polymorphism causes enhanced radical oxygen species production by human aldehyde oxidase. PLoS One 12:e182061.

Fu C, Di L, Han X, Soderstrom C, Snyder M, Troutman MD, Obach RS, and Zhang H (2013) Aldehyde oxidase 1 (AOX1) in human liver cytosols: quantitative characterization of AOX1 expression level and activity relationship. Drug Metab Dispos 41:1797-1804.

Hartmann T, Terao M, Garattini E, Teutloff C, Alfaro JF, Jones JP, and Leimkühler S (2012) The impact of single nucleotide polymorphisms on human aldehyde oxidase. Drug Metab Dispos 40 856-864.

Huang D-Y, Furukawa A, and Ichikawa Y (1999) Molecular cloning of retinal oxidase/aldehyde oxidase cDNAs from rabbit and mouse livers and functional expression of recombinant mouse retinal oxidase cDNA in Escherichia coli. Arch Biochem Biophys 364:264-272.

Hutzler JM, Yang Y-S, Brown C, Heyward S, and Moeller T (2014) Aldehyde oxidase activity in donor-matched fresh and cryopreserved human hepatocytes and assessment of variability in 75 donors. Drug Metab Dispos 42:1090-1097.

Kane MA, Folias AE, and Napoli JL (2008) HPLC/UV quantitation of retinal, retinol, and retiny esters in serum and tissues. Anal Biochem 378:71-79.

Kedishvili NY (2013) Enzymology of retinoic acid biosynthesis and degradation. J Lipid Res 54: $1744-1760$.

Napoli JL (2012) Physiological insights into all-trans-retinoic acid biosynthesis. Biochim Biophys Acta 1821:152-167.

Napoli JL (2016) Functions of intracellular retinoid binding-proteins. Subcell Biochem 81: $21-76$

Niederreither K, Vermot J, Schuhbaur B, Chambon P, and Dollé P (2002) Embryonic retinoic acid synthesis is required for forelimb growth and anteroposterior patterning in the mouse Development 129:3563-3574.

Noy N (2000) Retinoid-binding proteins: mediators of retinoid action. Biochem J 348:481-495. Paragas EM, Humphreys SC, Min J, Joswig-Jones CA, Leimkühler S, and Jones JP (2017) ecoAO a simple system for the study of human aldehyde oxidases role in drug metabolism. ACS Omega 2:4820-4827.

Pryde DC, Dalvie D, Hu Q, Jones P, Obach RS, and Tran TD (2010) Aldehyde oxidase: an enzyme of emerging importance in drug discovery. $J$ Med Chem 53:8441-8460.

Rashidi M-RR and Soltani S (2017) An overview of aldehyde oxidase: an enzyme of emerging importance in novel drug discovery. Expert Opin Drug Discov 12:305-316.

Silvaroli JA, Arne JM, Chelstowska S, Kiser PD, Banerjee S, and Golczak M (2016) Ligand binding induces conformational changes in human Cellular Retinol-binding Protein 1 (CRBP1) revealed by atomic resolution crystal structures. J Biol Chem 291:8528-8540.

Strelevitz TJ, Orozco CC, and Obach RS (2012) Hydralazine as a selective probe inactivator of aldehyde oxidase in human hepatocytes: estimation of the contribution of aldehyde oxidase to metabolic clearance. Drug Metab Dispos 40:1441-1448.

Terao M, Garattini E, Romão MJ, and Leimkühler S (2020) Evolution, expression, and substrate specificities of aldehyde oxidase enzymes in eukaryotes. J Biol Chem 295:5377-5389. 
Terao M, Kurosaki M, Barzago MM, Fratelli M, Bagnati R, Bastone A, Giudice C, Scanziani E, Mancuso A, Tiveron C, et al. (2009) Role of the molybdoflavoenzyme aldehyde oxidase homolog 2 in the biosynthesis of retinoic acid: generation and characterization of a knockout mouse. Mol Cell Biol 29:357-377.

Thatcher JE, Buttrick B, Shaffer SA, Shimshoni JA, Goodlett DR, Nelson WL, and Isoherranen N (2011) Substrate specificity and ligand interactions of CYP26A1, the human liver retinoic acid hydroxylase. Mol Pharmacol 80:228-239.

Tomita S, Tsujita M, and Ichikawa Y (1993) Retinal oxidase is identical to aldehyde oxidase. FEBS Lett 336:272-274.

Zhong G, Hogarth C, Snyder JM, Palau L, Topping T, Huang W, Czuba LC, LaFrance J, Ghiaur G, and Isoherranen $\mathrm{N}$ (2019a) The retinoic acid hydroxylase Cyp26al has minor effects on postnatal vitamin A homeostasis, but is required for exogenous atRA clearance. J Biol Chem 294 $11166-11179$
Zhong G, Kirkwood J, Won K-J, Tjota N, Jeong H, and Isoherranen N (2019b) Characterization of vitamin A metabolome in human livers with and without nonalcoholic fatty liver disease. J Pharmacol Exp Ther 370:92-103.

Ziouzenkova O, Orasanu G, Sharlach M, Akiyama TE, Berger JP, Viereck J, Hamilton JA, Tang G Dolnikowski GG, Vogel S, et al. (2007) Retinaldehyde represses adipogenesis and diet-induced obesity. Nat Med 13:695-702.

Address correspondence to: Nina Isoherranen, Department of Pharmaceutics, School of Pharmacy, University of Washington, Health Science Bldg., Rm. H-272M, Box 357610, Seattle, Washington 98195-7610. E-mail: ni2@uw.edu 